\title{
Viewpoint
}

\section{Sustainable Learning in Education}

\author{
Adar Ben-Eliyahu (1)
}

check for

updates

Citation: Ben-Eliyahu, A. Sustainable Learning in Education. Sustainability 2021, 13, 4250. https:// doi.org/10.3390/su13084250

Academic Editor:

David González-Gómez

Received: 3 March 2021

Accepted: 9 April 2021

Published: 11 April 2021

Publisher's Note: MDPI stays neutral with regard to jurisdictional claims in published maps and institutional affiliations.

Copyright: (C) 2021 by the author. Licensee MDPI, Basel, Switzerland. This article is an open access article distributed under the terms and conditions of the Creative Commons Attribution (CC BY) license (https:// creativecommons.org/licenses/by/ $4.0 /)$.
Faculty of Education, University of Haifa, Haifa 3498838, Israel; adarbe@edu.haifa.ac.il

\begin{abstract}
This article presents a theoretical definition and conceptualization of sustainable learning in education (SLE). SLE is differentiated from teaching for sustainability or sustainable learning, which focuses on teaching ways to renew, rejuvenate, and reuse necessary resources, such as clean water. At its core, SLE consists of strategies and skills that enable learners to effectively renew, rebuild, reuse, inquire, be open-minded, and cope with challenging and complicated circumstances that require learning and relearning. Four aspects of SLE are described: (1) renewing and relearning; (2) independent and collaborative learning; (3) active learning; and (4) transferability. To further understand SLE, the self-regulated learning framework is used. This is an important and novel future direction for research and educational practice.
\end{abstract}

Keywords: sustainability; learning; education; transferability; development

\section{Introduction}

Sustainable learning in education is a fairly new term with very little work or consensus related to its definition, assessment, or application [1-3]. It is critical to define sustainable learning in education (SLE) at the outset, as it differs from sustainable learning or sustainable development, which have been highly investigated and promoted in the last couple of decades. Whereas the term sustainable learning refers to the education and teaching of ways of living that enable sustainability-such as clean air and clean water (https:/ / www.sustainablelearning.com/teaching-resources; accessed on 11 April 2021) SLE is an emerging educational philosophy that refers to the curricula and methods of teaching and learning that provide individuals with the knowledge and know-how necessary for maintaining their learning in different circumstances (e.g., normalcy or crisis), during life transitions (e.g., from college to the workforce), and across different domains (e.g., math or literature; [1,2]). SLE includes teaching learners to be open-minded, inquire, reuse, renew, and rebuild to cope with complex and challenging circumstances that require learning and relearning. The learner is required to be active and vigilant, mindful and aware of external and internal conditions as part of ongoing assessments of their social and material world, acting effectively to better themselves and others. Teaching with an SLE-orientation aids educators in drawing out proactive and intentional learning from the individual as part of collaborative learning. Like sustainable energy, SLE is designed to equip learners with skills and strategies to renew themselves through inquiry, selfassessment, evaluation of their environment, and assessments of their social systems. In this way, learning is sustained throughout life as the world changes. Adopting an SLE approach is critical if we are to continue living on this earth, as the younger generations must acquire life skills that contribute to the ecological systems, their maintenance and thriving, and transfer their knowledge to older and new generations. Thus, the capacity to persevere and learn despite adversity and across contexts or situations is at the core of SLE. In what follows, SLE is defined and differentiated from sustainable learning and traditional learning. By applying pillars for sustainable resources and examining learning as a resource, four key aspects of SLE will be described. Applications of SLE in the field of education conclude the paper. 


\section{Defining Sustainable Learning in Education (SLE)}

There is some confusion in the literature in the definition of terms related to sustainable learning; thus, it is important to differentiate sustainable learning from sustainable learning in education (SLE) [1,4]. Part of the reason that there is ambiguity in using these two terms is that sustainable learning models tend to promote SLE features without explicitly defining the term sustainability $[1,2,5-7]$ (see Figure 1 for schematic). For example, the Recycling Education Center [8] used interactive educational activity pods about recycling issues to promote sustainable learning. Another example is the Burns Model of Sustainability Pedagogy [9] that promotes educating for sustainable and ecological living through transformative learning that implements elements of SLE, such as situated experiential learning, process-oriented learning, and learning that is transferable. However, even with applying the same principles of learning, the content of sustainable learning may be applied to chemistry or history, in which case SLE would be implemented, but not necessarily sustainability pedagogy.

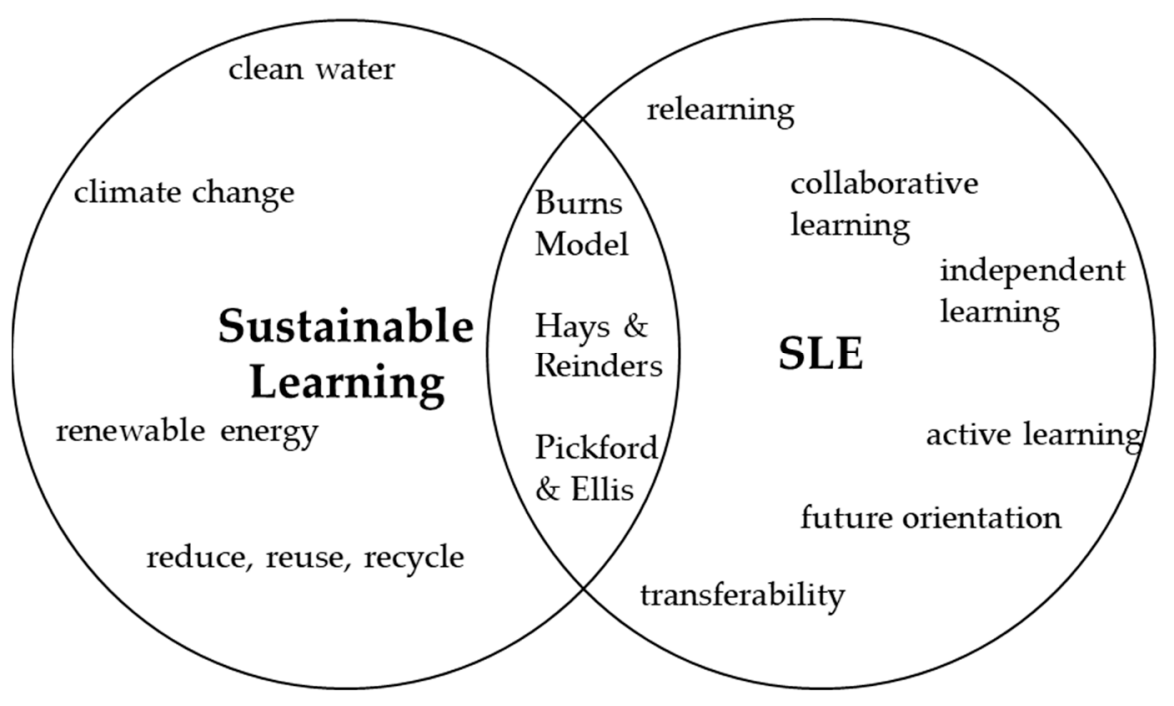

Figure 1. Schematic non-comprehensive presentation of overlaps and differences of sustainable learning and sustainable learning in education (SLE).

The reverse of this is also true, in that aspects of sustainable learning may be taught in traditional classrooms as a face-to-face interaction between one instructor and a group of students, imparting facts and figures through lectures and readings. This has essentially been the case for many decades when such traditional learning methods were used to teach content that is today considered part of the sustainability curriculum and pedagogy $($ see $[7,10])$. Traditional learning is considered structured and methodological, with little room for spontaneity or interactive, experiential learning. The rigidness of traditional learning is often contrasted with distance learning, learning that incorporates technological media such as videos and computer use [11-13]. However, this type of learning can incorporate into its content a sustainability pedagogy. Thus, it is evident that sustainable learning does not necessitate SLE, and SLE does not ensure sustainable learning.

Another approach to sustainable learning is in considering how learning environments contribute to global sustainability. Following the United Nations sustainable development goals [3], sustainable development has attracted considerable interest. Sustainable development has been described and implemented as devoting attention to children, youth development, and early education [14] to decrease disparities between wealthy and poverty-stricken minors. Making the case as others have done (e.g., [15]) that early childhood education has long-term benefits for the environment, Samuelson and Park discuss the importance of early childhood education for sustainability [16]. In this sense, early childhood education contributes to sustainable living; however, it is not necessarily 
sustainable education if it does not include information about how to care for the earth, nor is it SLE if it does not include teaching strategies and processes to enable learning durability across contexts, situations, and domains.

Sustainable learning focuses on basic consensus points about sustainability, such as the interrelations of socioeconomic and biophysical matters and their interdependency over time. It considers material durability and ecological damage, taking into account the notion that decision-makers and stakeholders may desire a trade-off that is not always good for the environment [10]. Sustainability deals with issues that cross the social-economyecology divide, such as health, security, community vibrancy, opportunities and choices, equity, resource maintenance, and efficiency. All of these may be taught in traditional or SLE classrooms.

This critical differentiation between content versus its delivery is the primary goal of the proposed conceptualization of SLE. Whereas sustainability assessments initially focused on materials, situations, and trends that are viable for the long run from a biophysicalecological perspective that considers the social and economic good, the current work has moved beyond this conceptualization. It now addresses sustainability assessments, also from a learning perspective [2], further muddying the definitional waters. The current paper seeks to unpack SLE components that can be used as an element of learning any domain, whether in the sustainability pedagogy or in other fields such as mathematics, chemistry, history, survival skills, or art. When acquiring SLE, the learner becomes selfsufficient, can self-evaluate their learning and its usefulness, adjust the learning content or process to align with their needs and aims. In this manner, a young gamer may learn how to build a Minecraft house by drawing on SLE skills similar to the way that an engineer may draw on SLE to invent an innovative and necessary tool. Thus, the goal of SLE is to impart learning strategies that are useful anywhere, anytime, and with regard to all content.

The primary distinction between sustainable learning or pedagogy and SLE is that sustainable learning is content-specific, imparting knowledge and understanding that relates to a sustainable world. The adjective sustainable describes the process of non-depletion and the capability of being "maintained at length without interruption or weakening" [17]. SLE implements these same principles of sustainability to the learning process itself; for SLE, the resource is learning rather than water, energy, or food. SLE empowers the learner to seek and generate new ideas while self-evaluating, a skill that becomes crucial during life transitions [5,6], necessitating new forms of thinking, behaving, and emotional coping. To this end, SLE considers learning to be resilient and responsive to global changes and maintains that durable learning skills and strategies can be taught. SLE does not directly address the notion of global citizenship, responsible economy, or sustainable energy; however, these forms of sustainability are promoted as learners focus on how to maintain and renew resources as a way of life through their SLE-related learning skills, especially by adopting healthy strategies and behaviors [18]. In implementing these strategies individually and in groups and transferring them across domains or situations, SLE promotes global sustainability by educating responsible thinkers and reflective citizens. Learners are challenged to correct their learning strategies on the fly and also to apply a feedforward loop, whereby strategies that facilitated past success are carried over to future tasks $[5,6]$. Thus, learning becomes a resource when conceptualizing SLE as comprising overarching learning strategies to produce self-sustenance and extend the longevity and durability of learning.

From an examination of the empirical research and conceptualizations of sustainability emerge four key components that cut across this literature. First, energy and resources are renewable; that is, methods have been identified that facilitate water or food to be reused or renewed. Thus, viewing learning as the resource to be renewed throughout lifelong learning and education becomes an important component of SLE [18,19]. This notion is referred to as renewing and relearning.

A second aspect recurrent in the literature is the interdependency of human and earth, highlighting the accountability and responsibility that humans have to learn how to 
maintain the durability of resources individually on a day-to-day basis and as a member of a wider community. Much work on sustainability refers to equipping the individual with the knowledge, methods, tools, and skills to maintain and create conditions for continuous and renewable energy, individually and collaboratively. This element is referred to as independent and collaborative learning.

A third tenet of sustainable living is taking action to maintain the earth's supplies. Humans are required to be active, initiate, and create solutions to ensure the sustainability of resources. Applied to learning, this would require active learning.

A fourth theme, repeated throughout the sustainable learning pedagogy literature, is the transferability of learning from formal to informal settings, or what may also be termed as lifelong learning. Whereas much work has highlighted the role of higher education in providing the skills to negotiate the transition to the job market, life transitions also transpire from one learning setting to another (e.g., the primary to secondary school transition). This also includes the transfer of training, such as how certain computer game strategies can be applied to analytic skills. To summarize, applying a sustainability lens to learning as a resource yields four key components of SLE: (1) renewing and relearning; (2) independent and collaborative learning; (3) active learning; and (4) transferability, as further described below.

\subsection{Renewing and Relearning}

An important tenet of sustainability is renewing one's resources when necessary. This core pillar of sustainable living and development is at the heart of sustainable learning. It promotes the reuse of the earth's resources to avoid depletion and prolong its durability. Applied to learning processes, this entails the renewing and relearning of relevant information and strategies and recognizing when something is no longer appropriate. Much effort is exerted into resource sustainability assessments [10], inquiring about the amount and quality of water, energy, and food. Comparable to the assertion that limited resources should be renewed or produced in new ways, learning itself can be viewed as a renewable resource capable of being relearned when necessary. Parallel to the need to assess the earth's resources, there is a need to assess one's learning and knowledge. This includes not just indicators of learning-such as grades or scores-but also self-reflection on what one knows or needs to know for future situations.

To self-reflect, individuals need to be aware of what they know and evaluate it in relation to what needs to be learned. Thus, much work on SLE emphasizes self-assessment [2]. Students monitor their progress, their learning and the gaps between what they know and what they should know, based on criteria determined by a course (e.g., history), by a need (e.g., how to use a new appliance), or by themselves (e.g., I want to learn about dolphins). This enables learning new things or relearning concepts that might have either been forgotten or that need to be relearned because of advancements in the field. For example, having learned how to use a certain computer program during a college course, a new workplace may necessitate relearning the program or updating to its newest version. This evaluation of "what do I know," "what don't I know," and "how can I use this knowledge to enhance my learning to achieve a goal," aligns with the umbrella term meta-processes, which encompasses the knowledge and know-how related to cognitive, behavioral, and affective learning strategies [20].

Self-assessment may also be shaped by others' evaluation. For example, one's supervisor may provide feedback regarding a certain topic or performance. Boud (2000) argues that sustainable assessment should be seen as part of lifelong learning [21]. One should be prepared to accept external assessments of familiar and novel learning tasks they encounter throughout their lives. Assessment may be provided by parents, teachers, peers or colleagues, supervisors, and even strangers (especially in today's online media). Assessment provides a standard against which learners may evaluate what needs to be renewed and relearned to align with current and changing demands. Of course, this may be met with considerable frustration, especially among younger ages, who have limited 
knowledge and experience related to learning [22]. Whereas older learners are more attuned to how learning works, younger learners are less experienced and may assume they are fully equipped to perform future tasks, even if the format has changed or time has elapsed. To this end, educators play a critical role [20] in explaining and preparing children and youth to accept new learning and relearning as part of SLE.

\subsection{Independent and Collaborative Learning}

For learning to be self-sustained, one needs to know how to learn on their own but also draw on their community when needed. Clearly, a self-sustained individual knows how to learn independently, whether through online or offline resources, experiences, or trial and error. SLE involves one's ability to seek social support and scaffolding when needed, balancing them with one's independent learning. To this end, it is important to consider learning's relational aspects, such as with peers, teachers, or parents, whether through faceto-face communication or online [20]. Independent learning involves learning by oneself -being autodidactic. This involves identifying what needs to be learned and finding sources for these topics. Whereas today's online learning facilitates autodidactic learning, the ability to seek help when necessary is critical [23,24]. The help-seeking literature highlights its importance as a management strategy in self-regulated learning [24] and as a resource for advanced students [25]. Help-seeking may be especially beneficial during uncertain and complex situations when learning must be sustained. In this way, independent learning and help-seeking align with the notion of sustainability as maintaining durable learning-a critical aspect of SLE.

Whereas in help-seeking, the learner approaches a more able other to inquire or request help, collaborative learning is conducted in a group or through interaction aimed at learning the same or similar topic. In this way, collaborative learning may involve people with different levels of knowledge; however, the responsibility for completing the task is more evenly distributed than in help-seeking situations. Thus, collaborative learning may involve joining course mates to study for an exam or complete a group project. Team-based tasks at the workplace are common, as are collaborations that advance science innovations, with each member contributing their expertise. Multi-disciplinary education has been viewed as a tool to enable collaborative work that involves all participants aiming to facilitate the desired outcome. Collaborative learning may also be embedded within a learning community or a "community of practice" [26], where the learner may rely on other students, family, friends, teachers, and mentors to complement their own shortcomings. Laszlo and Laszlo (2007) suggest that communities of knowledge are, in essence, sustainable learning communities [27], viewing learning as the process of acquiring and creating knowledge. When embedded within the dimension of intellectual capital, learning and its knowledge production become critical as an important global commodity, not only for producing and disseminating sustainable pedagogy but also as a product that renews and regenerates itself.

\subsection{Active Learning with a Future Orientation}

To ensure sustained learning, one must be an active participant in their own learning. Active learning refers to learners seeking information actively and intentionally. Active learners can monitor their progress by applying a feedback loop where they evaluate their headway and consider what remains to be done and what needs to be adjusted to continue effectively. Whereas a feedback loop refers to applying information to a current or ongoing task, a feedforward loop has been suggested as a process by which one notes to themself what should be done the next time the task is encountered [5]. Learners may self-evaluate or receive or solicit guidance and information from others (e.g., teacher or peer) on ways to improve, modify, or revise future performance.

This notion of a feedforward loop is at the heart of forward-thinking. Durable learning is achieved by reinventing and recycling resources in the changing global economy as well as planning ahead by implementing lessons learned and considering potential un- 
knowns and uncertainties. In this sense, providing students skills to evaluate and calibrate their future learning proactively is critical for sustainable development. By promoting feedforward thinking, a range of sustainability goals may be supported. To this end, SLE, implemented within formal education topics (e.g., mathematics, language), serves multiple objectives formulated by the UN regarding sustainable development goals [3]. As part of the feedforward loop, learners are active, taking the initiative to adjust and maintain aspects related to the learning task. Whereas inaction ensures retaining more of the same behaviors and habits, action enables recalibrating to accommodate society's needs. Thus, actively seeking and identifying what needs to be learned, what works and how certain things manifest are elements of SLE that are likely to transfer beyond the classroom.

\subsection{Transferability}

While feedforward loops refer to encountering similar tasks differently in the future, transferability refers to the ability to apply familiar strategies, processes, or skills in different domains or contexts [19]. For example, having learned to parse a large project into smaller steps for a history project, students may employ the same tactic to plan smaller chunks of learning for a chemistry exam. Transferability across contexts also refers to using skills learned in one setting (e.g., at school) in another setting (e.g., at work, at home). Transferring learning strategies and processes becomes crucial during life transitions, such as graduating from kindergarten to grade school, from primary to secondary school, or from college to the workplace. Much work has addressed these life transitions, seeking to identify the critical components that enable successful passage through them [28-30]. For example, work on school readiness identifies the critical transferable skills that would ensure a smooth transition from kindergarten to the school classroom [31,32]. These skills include planning, regulating emotions, controlling attention, and engaging in social behaviors [33]. In essence, these skills align with the conceptualization of SLE.

\section{Discussion}

The four key aspects of SLE (renewing and relearning, independent and collaborative learning, active learning, and transferability) are embedded, theoretically and empirically, in the self-regulated learning literature. In self-regulated learning (SRL) models, a loosely recursive feedback loop is described at the core of learning [20,34-38]. Learners articulate learning goals, either based on the curriculum, the individual's interpretation, planning, or on caring adults or peers. They adjust how their learning progresses from a content-related assessment as well as from self-reflection on their behaviors, cognitions, and emotions. Relying on self-assessment as part of learning, learners evaluate their progress toward learning goals and adjust their behaviors, cognitions, and emotions to achieve these goals. These strategies have been investigated as part of cognitive $S R L$, such as being able to shift and maintain focus $[35,39]$ or as various levels of processing [35,37]. Behavioral SRL refers to behavioral traces [40] or planning what and where to study [38].

Most recently, emotional SRL has been suggested as a strategy of thinking about a situation in a different light to regulate emotion as part of learning or as suppressing emotions that may hamper learning [34,35]. All of the SRL strategies and their implementation are executed by the student and scaffolded by people in their environment, such as teachers, peers, and parents. The knowledge and know-how related to such learning processes are part of metaprocesses [20]. These learning metaprocesses facilitate active calibration of learning to match the intended outcome. In today's dynamic world, flexibility and readjustment are critical. To a certain extent, this aligns with the 21st-century skills [41] that highlight the importance of flexibility, creativity, independent and collaborative learning, and different learning media.

As noted, the notion that learning may be taught through interactive processes that inform self-sustained strategies to elicit proactive, innovative, and change-ready learners is at the heart of SLE. By providing scaffolding for transferable learning that is resilient to adversity and can oscillate between different learning modes or media, we can create flexible, 
vigilant learners that can cope with changing situations (e.g., from normalcy to crisis [3]) or life transitions (e.g., from high school to college and to the workforce [2]). These two scenarios are quite different: changing ecological situations that result in catastrophe are collective in nature, whereas life transitions are personal, mainly affecting one's proximal systems. Both scenarios require maintaining learning and thriving with potentially far-reaching consequences. For ecological situations, learning is necessary for global sustainability and resilience, such as developing a vaccine under the pressure of the COVID-19 pandemic. For life transitions, personal crises may deplete one's resources, but learners who have been educated on self-sustenance strategies may adjust toward resilient learning [2].

In both situations, the capacity to self-reflect and readjust to achieve declared goals becomes critical. This cyclical loop between self-monitoring of progress and subsequent behavioral, cognitive, or emotional adjustments to reach the desired outcomes are at the heart of SRL. Whereas sustainable learning agendas may articulate the intended goal, SLE strategies may provide the methodology to advance these goals by applying effective learning processes.

Contributing to SLE is the knowledge and understanding students and their caring adults have of these learning processes, comprising a source of learning resilience. For example, knowing that one needs to write down words to memorize for a spelling test is reflective of one's understanding of how cognition works. Flavell (1979) termed this insight metacognition [42]. Extending this line of work, I recently termed metabehavior as the knowledge and understanding of behaviors [20]. An example of metabehavior may be knowing that remaining on-task requires closing internet browsers that invite unintentional surfing. Another important metaprocess is metaemotion - the knowledge and understanding one has of emotions. Building on prior clinical work with parent interviews that found that emotional scaffolding and coaching were associated with children's school success and well-being [43], I applied metaemotion to learning as the understanding and knowledge related to emotions that occur during or prior to performing a learning task [20]. Specifically, I proposed that an academic emotional learning cycle transpires, whereby emotions or affect felt prior to a learning episode shape emotional fluctuations and other subsequent learning processes. In this way, an individual's apprehension about starting college or coping with crisis-related stress shapes learning and its outcomes. For learning to be sustained despite these negative and sometimes paralyzing emotions, the learner must regulate emotions during the task as well as emotions external to the task. To this end, metaprocesses can be suggested to enhance SLE.

\section{Application to the Field of Education}

The proposed definition of SLE deepens our understanding of how to support learners' independent, active learning that can change and shift to accommodate different life demands and global circumstances. To this end, SLE provides a framework for considering the strategies and processes critical for ensuring learning throughout life, including the unknowns that await. The focus of SLE is on learning skills as a resource to be sustained rather than the particular learned content. To this end, SLE provides overarching strategies for ensuring self-sustenance in learning through renewing and relearning independently or in collaborative learning, the learner's active learning with a future orientation, and transference of learning strategies across domains and life's changing circumstances. This framework suggests that traditional learning, in which learning occurs through face-toface interaction with an instructor and a group of learners, may not be effective for SLE. For learning to be sustained in the real changing world, learners must be exposed to problem-solving experiences as part of their formal education.

While informal education may easily manifest activities to promote SLE, formal education may be more challenged to do so. To incorporate SLE into formal education, a starting point would be to structure courses to encourage active learning. Because learning is sustained by the active learner, educators may shape their course to promote self-initiated learning focused on development, in which students are encouraged to take risks and make 
mistakes as part of their desire to grow and develop from their learning process. To this end, the focus on their learning and growth aligns with the notion of a mastery focus or mastery goal orientation $[44,45]$.

Copious literature has delineated ways in which teachers can promote their students' focus on learning (mastery goal orientation). This line of study addresses the task components, the student's autonomy, teachers as guides that evaluate and provide feedback, time allotment, and group work $[46,47]$. Other techniques used to promote self-initiated inquiry-based group and independent learning of transferable strategies include projectbased [48] and flipped classrooms [49]. In both flipped classrooms and project-based learning, students take an active role outside of class, and the instructor becomes a guide for learning by helping their students navigate toward a learning goal and a defined outcome. These learning formats enable flexible, multi-dimensional learning characterized by open-mindedness, inquiry, renewal and rebuilding of knowledge, and flexibility to cope with complex and challenging questions and situations.

\section{Conclusions}

The novelty of the proposed SLE framework is twofold. On a practical level, teaching for sustainability and sustainable learning are distinctive processes. They are implemented differently and seek somewhat different outcomes. Whereas teaching for sustainability (i.e., sustainable pedagogy) focuses on retaining and renewing the earth's resources, SLE considers learning to be a major sustainable resource and delineates the skills and strategies to sustain learning in the face of changing and challenging situations. To this end, SLE is comprised of what have been termed 21st-century skills [41]. However, these skills and strategies are not linked to a century or a zeitgeist. Technologies and circumstances may change, but modes of thinking, creating, and problem-solving are rudimentary building blocks that can be instilled from a very young age [50].

An SLE framework provides a synergistic, integrative approach that can be applied across the learning literature and practices. More work needs to be done to specify critical transferable strategies and skills to be taught at different ages and grades. A range of methodologies should be applied, such as qualitative and quantitative methods, as well as retrospective and prospective inquiry in diverse and changing situations. Such work will have a considerable impact because SLE's focus on transferable skills empowers learners to acquire knowledge and processes to be applied during life transitions and crises, thus facilitating sustainable development and the capacity to navigate both stable and unforeseen situations.

Funding: This research received no external funding.

Institutional Review Board Statement: Not Applicable.

Informed Consent Statement: Not Applicable.

Data Availability Statement: Not Applicable.

Conflicts of Interest: The author declares no conflict of interest.

\section{References}

1. Hays, J.; Reinders, H. Sustainable learning and education: A curriculum for the future. Int. Rev. Educ. 2020, 66, 29-52. [CrossRef]

2. Peris-Ortiz, M.; Lindahl, J.M. Sustainable Learning in Higher Education: Developing Competence for the Global Marketplace; Springer: Berlin/Heidelberg, Germany, 2015.

3. United Nations. The Sustainable Development Goals Report. 2020. Available online: https://unstats.un.org/sdgs/report/2020/ (accessed on 11 April 2021).

4. Norden, B.; Avery, H. Global learning for sustainable development: A historical review. Sustainability 2021, 13, 3451. [CrossRef]

5. García-Jiménez, E.; Gallego-Noche, B.; Gómez-Ruíz, M.A. Feedback and self-regulated learning: How feedback can contribute to increasing students' autonomy as learners. In Sustainable Learning in Higher Education: Developing Competence for the Global Marketplace; Peris-Ortiz, M., Lindahl, J.M., Eds.; Springer: Berlin/Heidelberg, Germany, 2015; pp. 113-130. 
6. Rodríguez-Gómez, G.; Ibarra-Sáiz, M.S. Assessment as learning and empowerment: Towards sustainable learning in higher education. In Sustainable Learning in Higher Education: Developing Competence for the Global Marketplace; Peris-Ortiz, M., Lindahl, J.M., Eds.; Springer: Berlin/Heidelberg, Germany, 2015; pp. 1-20.

7. UN. Resolutions Adopted by the Conference. A/CONF.151/26/Rev.1. In Report of the United Nations Conference on Environment and Development, Rio de Janeiro, Brazil, 3-14 June 1992; United Nations: New York, NY, USA, 1993; Volume I. Available online: https:/ / www.un.org/esa/dsd/agenda21/Agenda\%2021.pdf (accessed on 25 March 2021).

8. Pickford, T.; Ellis, L. The creation of interactive activity pods at a Recycling Education Centre. Local Econ. 2015, 30, 370-381. [CrossRef]

9. Burns, H. Meaningful sustainability and learning: A study of sustainability pedagogy in two university courses. Int. J. Teach Learn. High. Educ. 2013, 25, 166-175.

10. Gibson, R.B. Sustainability assessment: Basic components of a practical approach. Impact Assess. Proj. Apprais. 2006, 24, 170-182. [CrossRef]

11. Hannay, M.; Newvine, T. Perceptions of distance learning: A comparison of online and traditional learning. Merlot J. Online Learn. Teach. 2006, 2, 1-11.

12. Nazarenko, A.L. Blended Learning vs. Traditional Learning: What Works? (A Case Study Research). Procedia-Soc. Behav. Sci. 2015, 200, 77-82. [CrossRef]

13. Engum, S.A.; Jeffries, P.; Fisher, L. Intravenous catheter training system: Computer-based education versus traditional learning methods. Am. J. Surg. 2003, 186, 67-74. [CrossRef]

14. Mesquita, C.; Lopes, R.P.; Garcia, J.A.; Rio Rama, M.C. First contact with the world of work: The competence built in the teaching practices. In Sustainable Learning in Higher Education: Developing Competence for the Global Marketplace; Peris-Ortiz, M., Lindahl, J.M., Eds.; Springer: Berlin/Heidelberg, Germany, 2015; pp. 75-88.

15. Heckman, J.J. Skill formation and the economics of investing in disadvantaged children. Science 2006, 312, 1900-1902. [CrossRef] [PubMed]

16. Samuelsson, I.P.; Park, E. How to educate children for sustainable learning and for a sustainable world. Int. J. Early Child. 2017, 49, 273-285. [CrossRef]

17. Merriam-Webster Online Dictionary. Available online: https://www.merriam-webster.com/dictionary/sustained (accessed on 25 March 2021).

18. Devece, C.; Peris-Ortiz, M.; Merigo, J.M.; Fuster, V. Linking the Development of Teamwork and Communication Skills in Higher Education. In Sustainable Learning in Higher Education: Developing Competence for the Global Marketplace; Peris-Ortiz, M., Lindahl, J.M., Eds.; Springer: Berlin/Heidelberg, Germany, 2015; pp. 63-73.

19. Tractenberg, R.E.; FitzGerald, K.T.; Collmann, J. Evidence of sustainable learning from the mastery rubric for ethical reasoning. Educ. Sci. 2017, 7, 2. [CrossRef]

20. Ben-Eliyahu, A. Academic emotional learning: A critical component of self-regulated learning in the emotional learning cycle. Educ. Psychol. 2019, 54, 84-105. [CrossRef]

21. Boud, D. Sustainable assessment: Rethinking assessment for the learning society. Stud. Contin. Educ. 2000, 22, 151-167. [CrossRef]

22. Pintrich, P.R.; Zusho, A. The Development of Academic Self-Regulation: The Role of Cognitive and Motivational Factors. In The Development of Achievement Motivation; Academic Press: Cambridge, MA, USA, 2002.

23. Karabenick, S.A.; Berger, J.L. Help seeking as a self-regulated learning strategy. In Applications of Self-Regulated Learning across Diverse Disciplines: A Tribute to Barry J. Zimmerman; Bembenutty, T.J.C., Kitsantas, A., Eds.; IAP Information Age Publishing: Charlotte, NC, USA, 2013; pp. 237-261.

24. Karabenick, S.A.; Gonida, E.N. Academic help seeking as a self-regulated learning strategy. In Handbook of Self-Regulation of Learning and Performance; Alexander, P.A., Schunk, D.H., Greene, J.A., Eds.; Routledge: New York, NY, USA, 2018 ; pp. 421-433. [CrossRef]

25. Zimmerman, B.J.; Martinez-Pons, M. Student differences in self-regulated learning: Relating grade, sex, and giftedness to self-efficacy and strategy use. J. Educ. Psychol. 1990, 82, 51-59. [CrossRef]

26. Wenger, E. Communities of Practice. Learning, Meaning, and Identity; Cambridge University Press: Cambridge, UK, 1998.

27. Laszlo, K.C.; Laszlo, A. Fostering a sustainable learning society through knowledge-based development. Syst. Res. Behav. Sci. 2007, 24, 493-503. [CrossRef]

28. Benner, A.D. The transition to high school: Current knowledge, future directions. Educ. Psychol. Rev. 2011, 23, 299-328. [CrossRef] [PubMed]

29. Eccles, J.S. Schools, academic motivation, and stage-environment fit. In Handbook of Adolescent Psychology; Lerner, R.M., Steinberg, L., Eds.; John Wiley and Sons: Hoboken, NJ, USA, 2004; pp. 125-153.

30. Mizelle, N.B.; Irvin, J.L. Transition from Middle School into High School. Middle Sch. J. 2000, 31, 57-61. [CrossRef]

31. Gaynor, A.K. Development toward school readiness: A holistic model. J. Educ. 2015, 195, 27-40. [CrossRef]

32. Sheridan, S.M.; Knoche, L.L.; Edwards, C.P.; Bovaird, J.A.; Kupzyk, K.A. Parent engagement and school readiness: Effects of the Getting Ready intervention on preschool children's social-emotional competencies. Early Educ. Dev. 2010, 21, 125-156. [CrossRef]

33. Office of Head Start. The Head Start Child Development and Early Learning Framework: Promoting Positive Outcomes in Early Childhood Programs Serving Children 3-5 Years Old. 2010. Available online: https://files.eric.ed.gov/fulltext/ED547179.pdf (accessed on 11 April 2021). 
34. Ben-Eliyahu, A.; Linnenbrink-Garcia, L. Extending Self-Regulated Learning to Include Self-Regulated Emotion Strategies. Motiv. Emot. 2013, 37, 558-573. [CrossRef]

35. Ben-Eliyahu, A.; Linnenbrink-Garcia, L. Integrating the regulation of affect, behavior, and cognition into self-regulated learning paradigms among secondary and post-secondary students. Metacognition. Learn. 2015, 10, 15-42. [CrossRef]

36. Pintrich, P.R. A conceptual framework for assessing motivation and self- regulated learning in college students. Educ. Psychol. Rev. 2004, 16, 385-407. [CrossRef]

37. Winne, P.H.; Hadwin, A.F. Studying as self-regulated learning. In Metacognition in Educational Theory and Practice; Hacker, D.J., Graesser, A.C., Eds.; Erlbaum: Hillsdale, NJ, USA, 1998; pp. 277-304.

38. Zimmerman, B.J. Goal setting: A key proactive source of academic self-regulation. In Motivation and Self-Regulated Learning: Theory, Research, and Applications; Schunk, D.H., Zimmerman, B.J., Eds.; Lawrence Erlbaum: New York, NY, USA, 2008 ; pp. $267-295$.

39. Schunk, D.H. Metacognition, self-regulation, and self-regulated learning: Research recommendations. Educ. Psychol. Rev. 2008, 20, 463-467. [CrossRef]

40. Azevedo, R. Defining and Measuring Engagement and Learning in Science: Conceptual, Theoretical, Methodological, and Analytical Issues. Educ. Psychol. 2015, 50, 84-94. [CrossRef]

41. Binkley, M.; Erstad, O.; Herman, J.; Raizen, S.; Ripley, M.; Miller-Ricci, M.; Rumble, M. Defining Twenty-First Century Skills. In Assessment and Teaching of 21st Century Skills; Griffin, P., McGaw, B., Care, E., Eds.; Springer: Berlin/Heidelberg, Germany, 2012. [CrossRef]

42. Flavell, J.H. Metacognition and cognitive monitoring: A new area of cognitive-developmental inquiry. Am. Psychol. 1979, 34, 906-911. [CrossRef]

43. Gottman, J.M.; Katz, L.F.; Hooven, C. Parental meta-emotion philosophy and the emotional life of families: Theoretical models and preliminary data. J. Fam. Psychol. 1996, 10, 243-268. [CrossRef]

44. Midgley, C.; Anderman, E.; Hicks, L. Differences between elementary and middle school teachers and students: A goal theory approach. J. Early Adolesc. 1995, 15, 90-113. [CrossRef]

45. O'Keefe, P.A.; Ben-Eliyahu, A.; Linnenbrink-Garcia, L. Shaping achievement goal orientations in a mastery-structured environment and concomitant changes in related contingencies of self-worth. Motiv. Emot. 2013, 37, 50-64. [CrossRef]

46. Ames, C. Achievement goals and the classroom motivational climate. In Student Perceptions in the Classroom; Schunk, D.H., Meece, J.L., Eds.; Lawrence Erlbaum Associates: Hillsdale, NJ, USA, 1992; pp. 327-348.

47. Epstein, J.L. Effective schools or effective students: Dealing with diversity. In Policies for America's Public Schools: Teachers, Equity, and Indicators; Haskins, R., MacRae, D., Jr., Eds.; Ablex Publishing: Westport, CT, USA, 1988; pp. 89-126.

48. Bell, S. Project-Based Learning for the 21st Century: Skills for the Future. Clear. House 2010, 83, 39-43. [CrossRef]

49. Enfield, J. Looking at the Impact of the Flipped Classroom Model of Instruction on Undergraduate Multimedia Students at CSUN. TechTrends 2013, 57, 14-27. [CrossRef]

50. Perry, N.E. Recognizing early childhood as a critical time for developing and supporting self-regulation. Metacogn. Learn. 2019, 14, 327-334. [CrossRef] 